\title{
Longitudinal Effects of Verbal Ability, Memory Capacity, and Phonological Awareness on Reading Performance
}

\author{
Jan Carol Näslund \\ Wolfgang Schneider \\ University of Würzburg, F.R.G.
}

\begin{abstract}
This study addresses the longitudinal relationship among verbal ability, memory capacity, phonological awareness, and reading performance. Data from 92 German children were used to explore the exact relation among these variables. Indicators of verbal ability, memory capacity, and phonological awareness were assessed in kindergarten and again after the first grade. The interrelationships among these factors, and the subsequent influence they have on decoding speed and reading comprehension during the second grade were examined via structural equation modeling procedures. Overall, the results of the longitudinal analyses show that the relationship of memory capacity and phonological awareness remains stable over time, and that memory capacity predicts performance on phonological awareness tasks in both kindergarten and second grade. Phonological awareness proved to be a significant predictor of decoding speed, which in turn considerably influenced reading comprehension.
\end{abstract}

\section{Introduction}

Previous research has demonstrated that development of reading skills depends on an integration of various factors. Some of these factors begin to affect children's readiness to read before formal reading instruction begins, and continue to affect children's performance during reading acquisition. In recent years, efforts have been made by researchers to discover cognitive processes which are uniquely related to, and good indicators of reading performance. The two factors cited most as being specifically related to reading performance are phonological awareness and memory capacity. These two factors have been handled largely independently in the literature.

This study was supported by a fellowship given the first author from the Alexander-von-Humboldt Foundation in Bonn, West Germany. Appreciation is extended to Angelika Weber and Anne Weinert for helping adapt measures to German children, Ronald Kinney, Andreas Schmidt, and Herman Schneider for computer programming, and Prof. Franz Weinert, Prof. Hans Brügelmann, and Dr. Harald Marx, and two anonymous reviewers for valuable commentary on early versions of this paper. 
Bradley and Bryant (1985; Bryant, Bradley, MacLean, \& Rossland 1989), Lundberg, Olofsson, and Wall (1980), Tunmer and Nesdale (1985), and Wagner, and Torgesen (1987) have demonstrated that phonological awareness (the ability to detect and differentiate phonemic units in speech) in preschool years is a very good predictor of children's later reading performance in school. Stanovich, Cunningham, and Feeman (1984) investigated the relationships of phonological awareness, verbal ability (listening comprehension), intelligence, and decoding speed concurrently with reading instruction in first, third and fifth grade. It appeared that phonological awareness had a very strong influence on decoding speed. Stanovich, Cunningham, and Feeman (1984) found a significant direct effect of listening comprehension on reading, but this influence was small in comparison to the influence of decoding speed, which in turn is significantly influenced by phonological awareness skills.

A strong connection between memory processes and reading ability has also been established (Daneman \& Blennerhassett, 1984; Dixon, LeFevre, \& Twilley 1988; Perfetti \& Lesgold, 1978; Yuill, Oakhill, \& Parkin, 1989). Siegel and Linder (1984), and Siegel \& Ryan (1988) have isolated deficits in verbal memory skills believed to be specifically related to reading (e.g. sensitivity to grammatic structures), as compared with other types of memory deficits (e.g. specific to arithmetic) or attention problems.

The exact relationship between memory processes and phonological awareness and their influence on orthographic decoding skills, as well as reading comprehension in general is not fully understood as yet, although in recent years considerable progress has been made in this direction. It is believed that beginning readers do not generally demonstrate a great amount of automaticity in reading, including automatic retrieval of grapheme-phoneme relationships, until they have extensive practice with these skills. LaBerge and Samuels (1974), and Guttentag \& Haith (1980) proposed that as particular reading skills become more and more practiced, memory capacity for what is read is enhanced, thus increasing the efficiency of processing text, the end result being better comprehension, without an overload on limited memory capacity.

This efficiency of processing is likely related to children's development of phonological awareness. A series of studies done by Kleiman (1975) demonstrated that during the act of reading, meaning of words and phrases are accessed from a reader's lexicon. After this lexical access process, the sequence of text is recoded phonologically for processing and retention in working memory. Brady, Mann, and Schmidt (1987), Brady, Shankweiler, and Mann (1983), Mann, Liberman, and Shankweiler (1980), and Shankweiler, Liberman, Mark, Fowler, and Fischer (1979) have since demonstrated an effect of phonological recoding on working memory, and shown that better readers use more phonological cues than poorer readers in storage of verbal information.

Many tasks designed to measure phonological awareness among pre-readers and beginning readers, such as providing rhymes, recognizing when two words share a common sound (Stanovich, Cunningham, \& Cramer, 1984), or detecting differences among groups of words (Bradley \& Bryant, 1985), normally require subjects to perform some recoding of cues into speech parts. Levels of phonological awareness are therefore expected to be evidenced by performance on such phonological recoding tasks. A high level of phonological awareness at the time children begin reading instruction can have positive effects on development of the phonological recoding skills needed for fluent reading.

However, before the recognition of grapheme-phoneme (e.g. letter-to-sound) relationships becomes automatic through experience with reading, tasks requiring phonological awareness and recoding likely require conscious effort for the beginning reader. As phoneme-grapheme relationships become more automatic after much practice with reading, phonological recoding also likely becomes an automatic process requiring much less conscious effort for the experienced reader in contrast to the novice.

Another issue strongly related to predicting performance of early reading is the presence or absence of preschool letter knowledge or early literacy. Although Bradley and Bryant (1985) and Lundberg, Olofsson, \& Wall (1980) have demonstrated phonological awareness in preschool children, Read, Yun-Fei, Hong-Yin, and Bao-Qing (1986), and Morais, Cary, Alegria, \& Bertelson 
(1979) claim that the phonological awareness associated with reading cannot develop in the absence of grapheme-phoneme knowledge. Comparisons of phonological awareness tasks within cultures that vary on exposure to alphabetic language (Read et al., 1986) and samples of literate and non-literate adults (Morais et al., 1979) call into question whether performance of phonological awareness tasks is possible without some alphabetic training. If such knowledge is necessary, or an important factor in development of phonological awareness, then it should demonstrate a significant influence in models of reading acquisition (see Ehri, 1989; Valtin, 1984).

\section{Longitudinal study of factors effecting later reading performance}

Results of a longitudinal study with 92 German children (Schneider, Näslund, \& Weinert, 1989) are used here to compare the impact of various factors, measured in kindergarten and again in early elementary school, on reading comprehension and decoding speed. In light of the research reviewed here, we proposed and tested various longitudinal models of reading and reading related factors. Along with other researchers (e.g. Stanovich et al., 1984), we expected that reading comprehension will be directly influenced by decoding skill, and that phonological awareness will have a direct effect on decoding speed. We also hypothesized that memory capacity could have a direct effect on performance of phonological awareness tasks. The direct effect of memory capacity on reading and phonological recoding likely begins to factor less heavily in the later grades, as children learn about and rely more on phonological recoding for processing and retaining text in working memory. As in most previous studies, measures of verbal ability were also included in order to assess the impact of a more distal predictor of reading acquisition on developmental changes in decoding speed and reading comprehension.

We tested these and alternative hypotheses of reading and reading-related factors in order to ascertain the stability of relationships among factors measured both before reading instruction begins, and again after a full year of reading instruction. The amount of stability of relationships among factors between preschool and early elementary school indicates the degree to which these continue to affect later reading performance in school, as well as the degree to which learning of specific verbal and reading skills in the early grades mediates the influence of preschool differences.

\section{Method}

Subjects. Our data were from 92 German children participating in the Longitudinal Study of the Genesis of Individual Differences (LOGIC, see Weinert \& Schneider, 1987 for a detailed description). Only children who had been administered all measures used in the kindergarten and elementary school measurement periods were included in the analyses. About $50 \%$ of the children came from within the city of Munich, and $50 \%$ were from nearby suburbs.

It should be noted that children in the Munich area are, as a rule, not taught the alphabet or any other reading skills during kindergarten. Parents are also discouraged from teaching their children to read before they enter the first grade. Therefore, it was not surprising that no readers were found among our sample of children. The average number of letters recognized was under six (median $=3$ ) in our sample at the end of kindergarten (mean age $=6.1$ years). In a word recognition test, the average number of words recognized was 1.0 (standard deviation $=1.2$ ). These words were taken from commercial product logos which children had correctly identified in a recognition test. Given that the majority of children in our sample had little letter knowledge, the actual overall impact of letter knowledge on other factors in our models of reading acquisition was low (Näslund \& Schneider, 1989).

Administration of measures. Testing for all measures, except for reading comprehension, was conducted individually at one of two test sites (one in Munich and one in a suburb). Those administering the tests (all women) were all familiar with the local Bavarian dialect. 
Reading comprehension measures were administered to all children in the classrooms in which they attended.

The memory capacity measures used here (word span tasks) were given at both measurement points. The verbal ability tests were age-corrected parallel forms of the same test for kindergarten and early elementary grades. The phonological awareness measures for the second grade differed from the tests given in preschool. The tasks given in second grade were much more difficult than the preschool measures in order to differentiate among the phonological skills of second graders. The reading comprehension and decoding speed measures were given twice, once at the beginning of second grade, and once in the last half of second grade. Comprehension and decoding scores from the beginning of second grade were used as dependent measures or models with preschool factors. Reading comprehension and decoding scores from the second half of second grade were used as dependent measures for models with the elementary school factors.

\section{Preschool measures}

General verbal ability was measured by the verbal section of he Hannover-Wechsler Intelligence Test (HAWIVA) for preschoolers (Eggert, 1978). This section includes vocabulary and verbal comprehension items.

Verbal memory capacity. Two word span tasks were given.The first word span task was an adaptation from Case, Kurland, and Goldberg (1982). Ten sets of one-syllable words were created from a set of seven concrete nouns. The set sizes varied between three and seven items. Beginning with sets of three words, two trials were given for each set size. Children were instructed to first listen to the entire set, then repeat the words they heard. Responses were scored according to the number of correct words repeated, regardless of sequence. A second word span test was devised, similar to the first, consisting of retention for one-syllable words which were phonologically similar. The lists of words either rhymed or began with the same letter.

Phonological awareness tasks. The children were given a variety of tasks to measure phonological awareness in kindergarten. Not all of these are included here due to methodological considerations. For example, a few tests correlated very highly with later reading performance, but children's mean performance was at ceiling (i.e., providing rhyming words) or floor level (i.e., phoneme blending), or was not normally distributed. Those phonological awareness tasks which demonstrated normally distributed results, and thus were included in our models are as follows:

Phonological oddity measures. A German version of Bradley and Bryant's (1985) phonological oddity measure was devised (Schneider, Sodian, Strube, \& Weinert, 1987). Only real words were used. This test was devised by Bradley and Bryant as a test of phonological awareness.

a) First sound oddity. For nine sets of four words each, the task was to identify the word with a different first sound. All words were one syllable. The target word always shared the middle phone with the other three words (Example: Fest Feld Fels Helm). This task was introduced to the child with a game. The experimenter said to the child, «I see something you don't see. It begins with a 'b'. Bank (trans. bench). Right?». After an affirmation from the child, the experimenter continued to give examples, but finally gave an inappropriate example. If the child did not respond that the word provided was incorrect, the experimenter explained that the word did not begin with a 'b'. This procedure continued until the child indicated when the experimenter said an inappropriate word. (It was very rare that children did not eventually spontaneously respond that a word was inappropriate). Two trials with 
with sets of four words were give as practice, followed by the nine experimental trials. No assistance was given during the experimental trials.

b) End sound oddity. The same experimental procedure, but with a different preparatory game was carried out for nine sets of four words, where one word had a different end sound as the other three. The three non-target words rhymed, and the target word always shared the same middle phone as the other three words (Example: Speck Dreck Stern Fleck). This task was introduced by a rhyming game, that also entailed the child the judge whether the experimenter was correct in producing rhyming words. The experimenter would point out when she made errors in rhyming if the child did not spontaneously do so. After the child spontaneously recognized when the experimenter made an error in rhyming, two trials with four sets of words each were given, followed by nine experimental trials ${ }^{1}$.

c) Syllable-connecting. This task was devised by Brügelman (1984) as part of an inventory of phonological encoding tasks. The child was introduced to a «robot» which spoke strangely. It segmented all the words, saying them all syllable by syllable. The child's task was to help the assistant decipher what the robot said. All words used in this task were real and assumed familiar to the children. For each of the phonological tasks the child received one point for each correct answer.

\section{Early elementary school measures}

General verbal ability. The verbal section of the Hamburg-Wechsler Intelligence Test (HAWIK) for elementary school (Tewes, 1985) was given. This test is the parallel form for the HAWIVA test given in kindergarten.

Verbal memory capacity. The same two measures for word span given in kindergarten were repeated in the second grade.

Phonological awareness. These measures were developed to measure both awareness of phonemic changes, and skill in phonemic recoding. These were administered in the last half of second grade.

a) Recognition of phonemic change. Children were asked to attend to two «Zauberwörter» (magic words) about to be played on the tape recorder, and to listen carefully to hear of the two words differed in any way. After playing the first pair of pseudowords, the assistant asked the child if he or she heard a difference between the two. If the child said «yes», he or she was asked to name the sounds which differed. Answers of letter names were accepted as correct. If the child said "no», the assistant repeated the words aloud until the child noticed the two were different, which almost all children did. Then the child was asked to listen to the words one more time, then say at least one of the sounds that differed between the two words. The two pseudowords were repeated on the tape recorder. If the child did not spontaneously answer, the assistant gave verbal prompts (such as: Can you name one sound that's different?) After this example, nine word pair trials were given. Two repetitions of each word pair, with 4 seconds between each pair were played without interruption for each experimental trial.

Pseudowords were constructed with common letter combinations found in German, but which would not be confused with real words. Two of the nine pairs of pseudowords were identical. If the child answered that either of these two pairs were different, he or she was also asked to name at any of the sounds that differed between the two words. These trials were used as indicators of response bias. Children were given one point for correctly naming at least one sound which differed in each of the seven differing word pairs. It should be noted that in contrast to English, German letter and letter combinations have very distinct and stable pronunciations. The name of a German letter includes the 
sound of the letter, and vowel names and sounds are identical. Although most children in the second grade read aloud and use letter-sound correspondences in high German, children's responses were considered correct in the few cases where children named phonemes or pronounced pseudowords in Bavarian dialect.

In the case of consonant changes, children responded most of the time with letter-sounds and not letter-names. This indicated that children were approaching this task as a test of sensitivity to sound, and did not likely need to concentrate on spelling out the pseudoword cues in order to answer the task. This could not be assessed for vowels because the names and sounds are the same.

b) Manipulation of phones. This task consisted of two parts. First, the child listened to a two syllable tape-recorded nonsense word, said twice (with identical intonation). The child was asked to repeat the word, and the assistant repeated the word herself again for the child when it was not said correctly. The child was then asked to replace one of the sounds in the word with one provided by the assistant. For example, for the word "ANI", the child was asked to change the «i» sound to an «u» sound. One example and five experimental trials with similar word pairs were used. Three of the experimental trials required replacing a vowel ith a vowel, and two experimental trials required replacing a consonant with a consonant.

The second task, also consisting of one example and five experimental trials, required children to again listen to a two syllable word, but this time they were asked to switch the position of two sounds within the word. For three of the experimental trials, two consonants within the word were switched, and for two of the experimental trials, two vowels here switched. For each of the 10 experimental trials in these two tasks, children were given one point for each correct replacement or letter switch.

Word and pseudoword decoding speed. These tasks were based on Rott and Zielinski's (1984) German adaptation of Hogaboam and Perfetti's (1978) decoding speed tasks. This task was given at the beginning of second grade. 30 four letter words and 30 four letter pseudowords were presented in large letters (about four inches high) on a computer screen. All stimuli were one syllable.

Reading time was measured in milliseconds, beginning from the appearance of the word on the computer screen until assistants pressed a computer key just after the child completed each word, thus recording the decoding speed on a personal computer diskette. Each word remained on the screen until the child finished pronouncing all sounds. In pilot work, as well as in the study itself, children rarely made mistakes in pronouncing the real and pseudowords. Children varied greatly in the speed of pronouncing, but not in accuracy of reading the words appearing on the screen. This result could be due to the almost one-to-one correspondence of letter-to-sound in German.

Reading comprehension measures. This 30 item test was developed by the first author (Näslund, 1987) to measure word knowledge and comprehension within the context of single sentences and comprehension of longer text (short stories).

a) Word knowledge items (18) were multiple choice, with four choices per item. These involved finding synonyms, with some of the choices requiring word discrimination, and finding antonyms. All items required comprehension within the context of a sentence. (i.e., The context of each sentence defined the correct answer to be chosen.)

b) The text comprehension part consisted of five short stories (three to seven short sentences each) followed by two or three multiple choice questions, for a total of 12 multiple choice questions. The stories and questions were designed to test children's understanding of the text deducing answers from inferences based on information in the stories.

The same reading comprehension test was given at the beginning and during the last half of second grade to our subjects and to over 1200 second graders in Bavaria. The Cronbach 
Alpha reliability coefficients for all children for parts (a) and (b) of the comprehension test at both testing points ranged between .81 and .88 . The means of our subjects and the group of 1200 children did not significantly differ on either part of the comprehension test.

\section{Predictors of reading comprehension}

In order to more closely assess the relationships among factors, structural linear equations analyses were performed with all variables. This particular procedure tests predetermined hypotheses through estimates of the structural relationships among the variables, and the direction and magnitude of these relationships.

Comparing models of factors affecting reading performance. Model specifications. The computer program LISREL VI (Linear Structural Relationships, Jöreskog \& Sörbom, 1984) was used to analyze the influence of verbal ability, memory span, and phonological encoding on the reading-related measures decoding speed and reading comprehension) using the level of latent variables. LISREL makes use of structural equation modeling (i.e., causal modeling) procedures which serve to specify the causal links among the latent variables. This rocedure also allows for testing the measurement model; that is, the relationship between observed variables and unmeasured hypothetical constructs. Maximum likelihood estimates of measurement and causal parameters are obtained simultaneously; LISREL makes use of all information in the data about each parameter in generating its estimates. The efficiency of a given model is evaluated by a chi-square $\left(\chi^{2}\right)$ goodness-of-fit statistic which is a direct function of the discrepancy between the sample covariance matrix and that reproduced by the parameter estimates of the model. A small $\chi^{2}$ (relative to the degrees of freedom) indicates that the model provides a plausible representation of the causal process. Additionally, the goodness-of-fit index (GFI) and the root mean square residual (RMR) can be used as measures of overall fit of the data to the model. GFI is a measure of the relative amount of variance and covariance jointly accounted for by the model and should vary between zero and one, with higher scores indicating better fit. RMR is a measure of the average of the residual variance and covariance. Here, the more acceptable model is indicated by smaller values.

The same structural model was used for models consisting of kindergarten and second grade measures (see Figure 1). The models tested were constructed as follows:

1) The verbal ability construct consisted of the age-adjusted HAWIVA and HAWIK scores appropriate at each testing point.

2) The word span measures were used to create the verbal memory capacity factor.

3) The kindergarten phonological awareness factor consisted of the German adaptation of two of Bradley and Bryant's phonological oddity tasks, and Brügelmann's test of syllable combining. The phonological awareness construct for second grade consisted of two phonological tasks (recognizing phoneme changes and manipulation of phonemes).

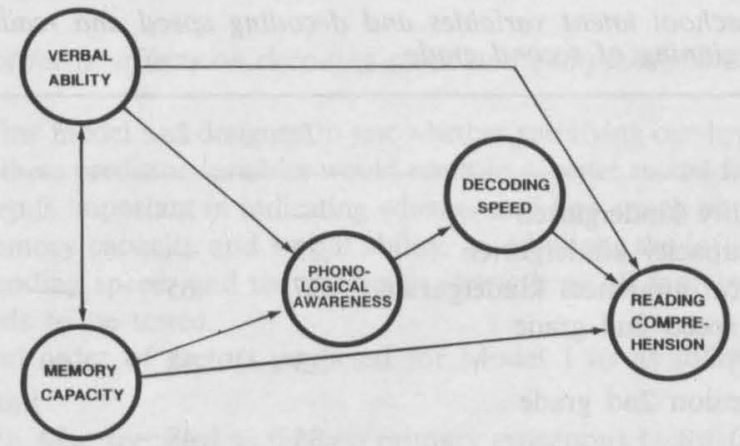

Figure 1. Structural equations model for predictors of reading comprehension 
4) The decoding speed factor for the beginning and last half of second grade consisted of the reading times for reading words and pseudowords.

5) Finally, reading comprehension for the beginning and last half of second grade was represented by the word usage and text comprehension subtests of Näslund's (1988) test.

\section{Results}

\section{Difference scores in repeated measures}

$T$-tests of repeated-measure difference were conducted for each of memory span, word decoding speeds, pseudoword decoding speeds, and reading comprehension measures between the two measurement points.

These $t$-tests control for intercorrelation and adjust the alpha-levels for repeated measures. Each mean comparison was significant beyond the $p<.005$ level. Performance on memory capacity, decoding speed, and reading comprehension tasks significantly increased between testing points for our sample.

The next step in the analyses entailed determining if the relationship among factors which we hypothesized holds true, and if this pattern of relationships remains stable during beginning reading performance.

\section{Correlations among factors}

With the use of the LVPLS program for latent variables path analysis with partial least-squares estimation (Lohmöller, 1981), an estimate was computed of the correlations among the factors defined by the groups of variables described in the last section. The preschool verbal ability, memory capacity, and phonological awareness factors, and the decoding speed and reading comprehension factors from the beginning of second grade intercorrelations are shown in Table 1. Correlations among the early elementary school latent factors are shown in Table 2.

These correlation matrices are based on the computed matrices of restricted inner residual variance among measures which define each factor and on the computed matrices of total effects among factors (see Lohmöller, 1981, for computations). The correlation matrices were taken from the LVPLS program and not from the LISREL program, because the LVPLS estimation are based on the model of total effects, and are therefore not affected by the particular specification and fixing of directional paths among factors.

Table 1

Correlations of preschool latent variables and decoding speed and reading comprehension measured in the beginning of second grade

\begin{tabular}{|c|c|c|c|c|c|c|}
\hline & & 1 & 2 & 3 & 4 & 5 \\
\hline 1 & Verbal ability kindergarten & - & & & & \\
\hline 2 & Memory capacity kindergarten & .33 & - & & & \\
\hline 3 & Phonological awareness kindergarten & .37 & .65 & - & & \\
\hline 4 & Decoding speed 2nd grade & & & & & \\
\hline & (beginning) & .13 & .38 & .49 & - & \\
\hline 5 & $\begin{array}{l}\text { Comprehension } 2 \text { nd grade } \\
\text { (beginning) }\end{array}$ & .35 & .48 & .50 & .63 & 一 \\
\hline
\end{tabular}


Table 2

Correlations of early elementary school latent variables and decoding speed and reading comprehension at the end of second grade

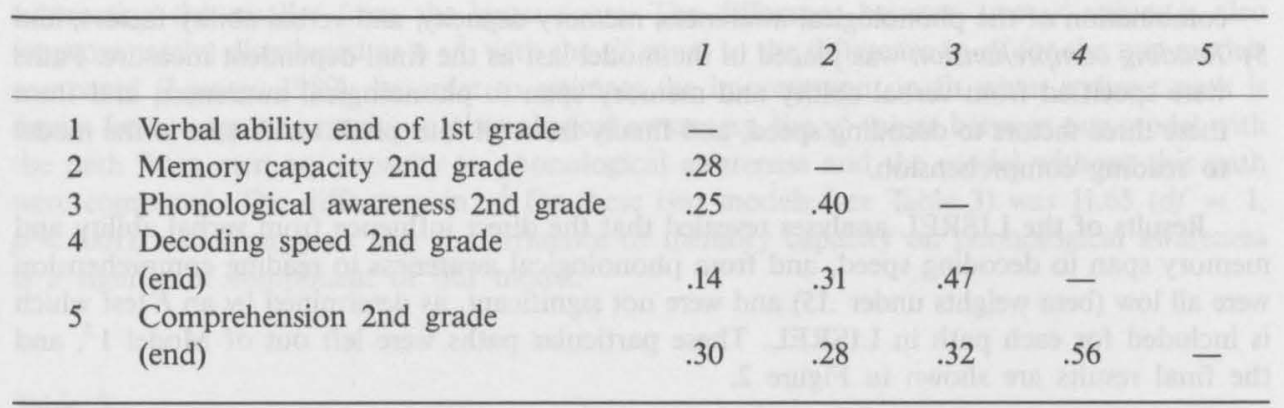

The largest correlation among the preschool factors appears between memory capacity and phonological awareness. This correlation is greatly reduced when these factors are compared again in second grade. As for the second grade factors, the highest correlation among these is between decoding speed and reading comprehension. For the correlations among factors that represent a two year span between measurements, preschool phonological awareness appears to have the largest correlation with later decoding speed, and both memory capacity and phonological awareness appear to correlate almost equally strongly with reading comprehension. This result supports the findings of other researchers that decoding speed is directly related to accessing phonological codes (Perfetti \& Lesgold, 1978; Siegel \& Ryan, 1988; Stanovich et al., 1984), and that reading comprehension is related to phonological awareness (Lundberg et al., 1980) and memory capacity (Daneman \& Blennerhassett, 1984; Dixon et al., 1988; Yuill et al., 1989). These correlations indicate that these relationships span over a two year period. It should be remembered that the phonological awareness factor was represented by different tasks at each measurement point, but these were intended to measure the same construct.

The major difference in the two matrices is that the relationships among almost all measures demonstrates a drop in magnitude during the second grade. This drop is not surprising given that all the children had received almost two years of instruction in reading by the second measurement point. It was expected that children demonstrate a greater interindividual variance in performance on prereading factors before formal instruction begins. The correlations between memory capacity and phonological awareness, and phonological awareness and decoding speed are still high at the end of second grade, which indicates that variance in memory capacity and phonological awareness still exist among the children in second grade, although this variance is not as great as in preschool.

Models of preschool factor affects on decoding speed and comprehension in the second grade

Model 1 . The first model was designed to test whether specifying our hypothesized structural relationship among these predictor variables would result in a better model fit than the regression type model. This step is important in indicating whether and how much phonological awareness is influenced by memory capacity and verbal ability. In addition, the influence of these three factors on later decoding speed, and the predictive strength of all four predictors on reading comprehension needs to be tested.

The hierarchical order of factors predicted for Model 1 as as follows:

1) Verbal ability, and

2) Memory capacity, were specified as the two primary exogenous factors in the model, which were specified to influence the other factors. 
3) Phonological awareness was specified as being influenced by verbal ability and memory span, and as having an affect on the following two factors:

4) Decoding speed was placed next in the model, and was expected to be influenced by a combination of the phonological awareness, memory capacity, and verbal ability factors; and

5) Reading comprehension was placed in the model last as the final dependent measure. Paths were specified from verbal ability and memory span to phonological awareness, and from these three factors to decoding speed, and finally from all four predictor factors in the model to reading comprehension.

Results of the LISREL analyses revealed that the direct influence from verbal ability and memory span to decoding speed, and from phonological awareness to reading comprehension were all low (beta weights under .15) and were not significant, as determined by an $F$-test which is included for each path in LISREL. These particular paths were left out of Model $1^{2}$, and the final results are shown in Figure 2.

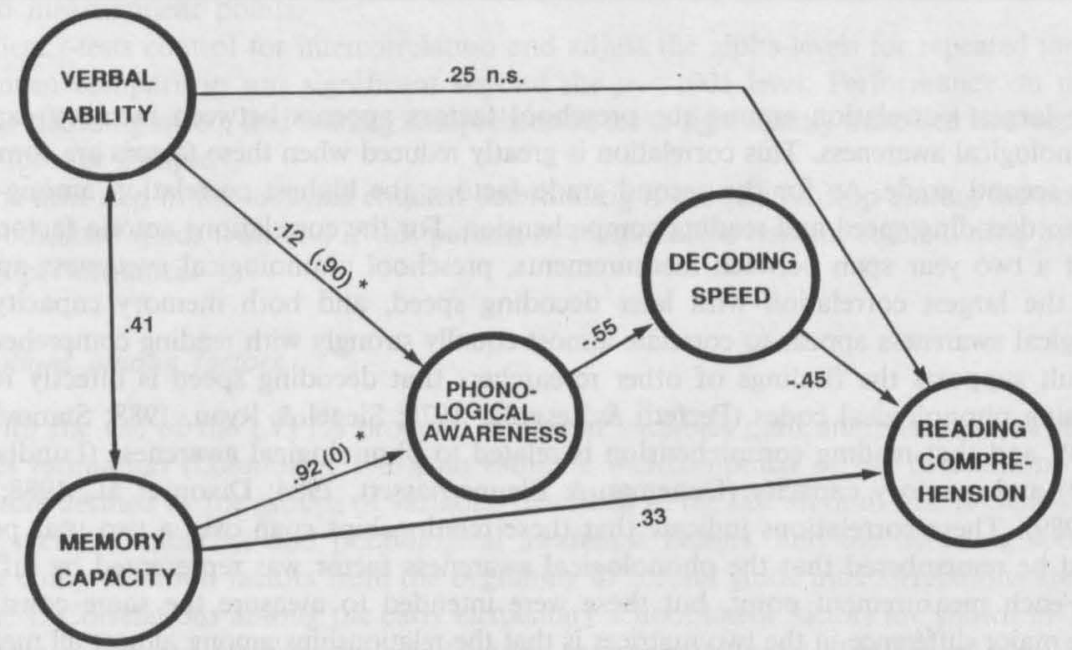

Figure 2. Structural equations model for preschool predictors of second grade decoding speed and reading comprehension (* Beta coefficients when the directional path between memory capacity and phonological awareness is set to zero)

The fit of Model 1, assessed by the goodness-of-fit index (GFI), root-square mean residual (RMR) and the relationship of the $\chi^{2}$ value with $d f$, attests to the strength of these structural relationships among factors. The GFI ranges from 00 to 1.00 , with larger numbers indicating better fit. RMR also ranges from .00 to 1.00 , with lower numbers indicating a good fit and low amounts of unexplained variance accounted for when testing the model. In addition, assuming an equal population size, the larger the $p$-value for $\chi^{2}$, the stronger the model is in explaining the structure of the data. The resulting $\chi^{2}$ for this model was 37.86 with 30 $d f(p$-value $=.15)$, GFI was .93 , and RMR was .07 .

Model 2. Testing the influence of memory span. In order to assess the importance of the effect of preschool memory capacity on phonological awareness in predicting decoding and reading comprehension in the second grade, Model 2 was specified such that the path leading from memory capacity to phonological awareness was removed. Resulting paths indicated that without the influence of memory capacity, intelligence significantly predicted phonological awareness (see Figure 2, values in parentheses). Although paths from phonological encoding to decoding speed, and from decoding speed to reading comprehension were also all shown to be significant without the path between memory capacity and phonological awareness, the 
fit of the model indicated that this pattern of relationships was not as adequate in explaining the structure of the data $\left(\chi^{2}=49.51, d f=31, p<.05\right)$ than our proposed model (1).

An estimate of the significance of difference between two $\chi^{2}$ values can be obtained by subtracting the smaller from the larger score. The difference between two $\chi^{2}$ values is also (approximately) distributed as a $\chi^{2}$, with the $d f$ equal to the difference in $d f$ for the two models compared (Lomax, 1989). In order to estimate the improvement in fit when a direct path is drawn from memory capacity to phonological awareness, the $\chi^{2}$ values between our model with the path from memory capacity to phonological awareness and the model without this path were compared. The difference in $\chi^{2}$ for these two models (see Table 3$)$ was $11.65(d f=1$, $p<.001$ ), which suggests that the influence of memory capacity on phonological awareness is a significant component of our model.

\section{Table 3}

Goodness-of-fit indices for all models

\begin{tabular}{|c|c|c|c|c|c|c|}
\hline & Model & $\chi^{2}$ & $d f$ & $p$ & GFI & RMR \\
\hline 1) & Preschool causal & 37.86 & 30 & .15 & .93 & .07 \\
\hline \multirow[t]{3}{*}{ 2) } & Preschool (no memory path) & 49.51 & 31 & $<.05$ & .91 & .09 \\
\hline & Model difference & & & & & \\
\hline & $2-1$ & 11.65 & 1 & $<001$ & & \\
\hline \multirow[t]{3}{*}{ 3) } & Preschool regression & 86.24 & 33 & $<.001$ & .84 & .21 \\
\hline & Model difference & & & & & \\
\hline & $3-1$ & 48.38 & 3 & $<.001$ & & \\
\hline 4) & 2nd grade causal & 29.60 & 22 & .13 & .94 & .06 \\
\hline \multirow[t]{3}{*}{ 5) } & 2nd grade (no memory path) & 42.46 & 23 & $<.01$ & .91 & .10 \\
\hline & Model difference & & & & & \\
\hline & $5-4$ & 12.76 & 1 & $<001$ & & \\
\hline
\end{tabular}

Model 3. The third model consisted of five factors, three from preschool (verbal ability, memory span, and phonological wareness), and two from the beginning of second grade (decoding speed and reading comprehension). This particular model (Model 1) specified verbal ability, memory capacity, phonological awareness, and decoding speed as the four (exogenous) predictor factors, which affect reading comprehension. This particular model resembles a regression model, specifying no relationships among the predictor factors. Tests of simple regression models are useful to include in such modeling procedures for comparison with models that hypothesize specific direction of influence among factors. If a specified hypothetical causal model does not fit the structure of the data significantly better than a simple regression model of the factors, then one must question the significance of the causal model specified.

The resulting $\chi^{2}$ for the regression model was 86.24 , with $33 d f$, and a GFI of .84 (see Figure 3). From this regression model, it appears that preschool phonological awareness and second grade decoding speed have the largest influence on reading comprehension, as measured in second grade. Given that the $\chi^{2}$ value is so large in proportion to the degrees of freedom, 
resulting in a small $p$-value, this particular model does not likely represent the actual structure of relationships generated by the actual data.

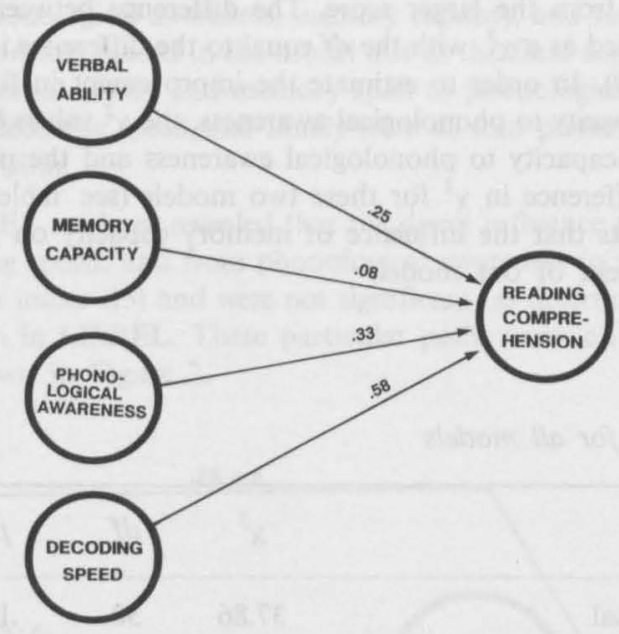

Figure 3. Regression model for effects of kindergarten factors and second grade decoding speed on second grade reading comprehension

Comparing our regression Model 3 with our hypothesized Model 1 gives a $\chi^{2}$ difference of 48.38 ( $d f=3, p<.001$ ) (see Table 3). This indicates that the model that specifies specific causal relationships among the predictor factors in addition to their affect on the dependent factor (reading comprehension) is a significant improvement compared to the model that specified the four predictor factors as exogenous factors.

Our next concern is whether the results concerning the relationships among these same factors also applies to similar models constructed and tested for the influence of verbal ability, memory capacity, and phonological awareness measured in the second grade on decoding speed and reading comprehension measured at the end of second grade.

\section{Second grade factors affecting reading performance}

Model 4. A five-component model parallel to the five-component model used to test relationships among preschool factors, and their effect on later decoding speed and reading comprehension was specified. This model (Model 4) consisted of the verbal ability, memory capacity, phonological awareness, decoding speed, and reading comprehension factors administered in second grade. The decoding and reading comprehension measures were taken in the last half of second grade.

The same procedure was carried out as that described for the preschool factor models. This model (see Figure 4) appears to fit the structure of the data, given the relationship between $\chi^{2}$ and $d f\left(\chi^{2}=29.60, d f=22\right)$. A similar pattern of results is found in comparison with models including the preschool factors (see Figure 3). However, the direct influence from memory capacity to reading is no longer significant in comparison with the preschool models. This result is consistent with the large drop in the correlation between these factors found in the second grade predictor factor correlations. In addition, verbal ability now has a significant direct influence on reading comprehension. This result is not predicted by the factor correlations. However, the drop in the direct influence of memory capacity on reading comprehension may have contributed to an increase in the estimated effect in our model for verbal ability. 


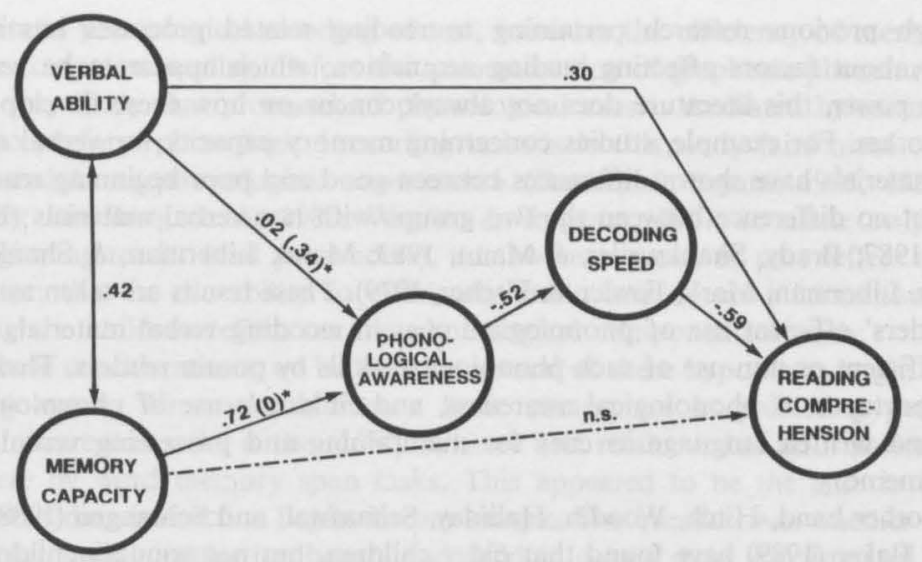

Figure 4. Structural equations model for second grade predictors of decoding speed and reading comprehension (* Beta coefficients when the directional path between memory capacity and phonological awareness is set to zero)

All paths which were significant in the preschool factor model (Model 1), except for the direct path between memory capacity and reading comprehension remained significant in the second grade factor model (Model 4). From these results, it appears that the relationship among predictor variables remains relatively stable. Verbal ability, memory capacity, and phonological awareness measured in kindergarten affect each other in a similar manner as when measured in second grade. Although memory capacity in the second grade no longer has a significant direct influence on reading comprehension, it continues to have an indirect influence through its strong influence on phonological awareness.

Model 5. Testing the strength of memory capacity. In order to test the strength of influence memory capacity has on phonological awareness in the second grade, an alternative model (Model 5) was constructed and tested which removed the path from memory capacity to phonological awareness. Without the influence of memory span, verbal ability yielded a significant influence on phonological awareness, as was the case in the preschool factor model. All other hypothesized paths remained significant in the model. However, this model does not seem to represent the structure of the data as well as our proposed model (Model 4) $\left(\chi^{2}=\right.$ $42.46, d f=23, p<.01$ ). Comparing the fit of this model with that shown in Figure 4 yields a significant difference in $\chi^{2}$ values $\left(\chi^{2}=12.76, d f=1, p<.001\right.$ ) (see Table 3). This indicates that the inclusion of the path from memory capacity to phonological awareness is a significant component of our model of factors affecting reading performance at the end of second grade, just as preschool memory capacity was demonstrated earlier to be an important factor.

\section{Discussion}

The major purpose of this paper was to compare and test several hypotheses concerning the longitudinal relationships among factor which are believed to affect early reading acquisition. Several studies have demonstrated the predictive power of preschool phonological awareness for later reading performance in school (Bradley \& Bryant, 1985; Lundberg et al., 1980). Some studies show a differential effect of verbal and non-verbal memory processes are specific to reading, as opposed to other school subjects (Dixon et al., 1988; Siegel \& Linder, 1984; Siegel \& Ryan, 1989). 
Although previous research pertaining to reading related processes has made several assumptions about factors affecting reading acquisition, which appear to be very important in predictive power, this literature does not always concur on how these develop and interact with one another. For example, studies concerning memory capacity for verbal materials and non-verbal materials have shown differences between good and poor beginning readers in verbal materials, but no difference between the two groups with non-verbal materials (Brady, Mann, \& Schmidt, 1987; Brady, Shankweiler, \& Mann, 1983; Mann, Liberman, \& Shankweiler, 1980; Schankweiler, Liberman, Mark, Fowler, \& Fischer, 1979). These results are taken as an indication of good readers' efficient use of phonological cues in recoding verbal material, as compared with the inefficient or non-use of such phonological skills by poorer readers. These researchers note the importance of phonological awareness, and children's use of phonological recoding of spoken and written language as cues for maintaining and processing verbal information in working memory.

On the other hand, Hitch, Woodin, Halliday, Schaafstal, and Schraagen (1988), and Hitch, Woodin and Baker (1989) have found that older children, but not younger children, make use of phonological attributes of speech for information storage. These studies compared performance of older children (10-11 years old) and preschoolers (5-6 years old) on memory for groups of objects, where some grouped objects had visually similar shapes, but dissimilar sounding names; some had names which were phonologically similar, but with visually dissimilar shapes and some groups had shapes and names which were dissimilar. One consistent result in these studies was that phonological similarity, but not similarity of shape, interfered for memory of objects for the older, but not the younger children. Hitch et al. $(1988,1989)$ believe that older children are more likely to use a verbal rehearsal strategy, and thus similar sounding object names could interfere with storage. Younger children are more likely to use visual rather than phonological cues for storage, and thus object similarity would interfere with their memory for objects.

In order to test whether any phonological interference effects existed with our own sample in early elementary school, we divided our sample of German children into two groups below and above median performance on the reading comprehension test. All children demonstrated better performance on the phonologically dissimilar lists than on the phonologically similar lists. Comparing the within reading-group difference between memory span for phonologically similar and phonologically dissimilar word lists reavealed less of a difference for the better readers in memory span $(M=.87$ less phonologically similar as dissimilar words recalled) than for the poorer readers ( $M=1.66$ less phonologically similar as dissimilar words recalled).

Althougth these results would seem to contradict those of Shankweiler et al. (1979), who have demonstrated a phonological interference effect using written and oral letter stimuli for children at the end of second grade, their study differs from our own given the assumption that most American children learn the letters (and likely the sounds) of the alphabet as early as preschool or kindergarten (at age 4 or 5). Most of our children had only one and a half years of experience with the alphabet and reading at the time of second grade testing, as compared with (probably) almost three years of such experience for children in the Schankweiler et al. study. Children in the Brady et al. (1983, 1987), and Mann et al. (1980) studies were in the third grade, and therefore a considerable amount of reciprocal development in factors affecting reading could have occured prior to their study, as well. It is debatable, thus a ripe issue for further study, how much reading experience is required before grapheme-phoneme relationships in encoding and decoding text becomes automatized, and thus demonstrates interference effects as found by Brady et al. (1983, 1987), Mann et al. (1980), and Shankweiler et al. (1979).

The effect of phonological recoding on memory capacity for children is likely not present in children as they first tackle learning to read. Case, Kurkland, and Goldberg (1982) have shown that experience increases the efficiency with which one processes and, in turn, retains information. Experience and eventual automatization of grapheme-phoneme relationships, which 
in turn facilitates phonological recoding of text, increases the efficiency of memory processes necessary for competent reading. Before this automatization of grapheme-phoneme relationships occurs, it is very likely that processes of phonological cues is mediated by memory capacity. The ability to perform phonological recoding tasks is in this study (and most often in other studies) referred to as phonological «awareness» (Bradley \& Bryant, 1985, 1988; Gough \& Juel, in press; Lundberg et al., 1980; Wagner \& Torgesen, 1987, to name only a few). For the most beginning reader (and pre-readers), this awareness may in part reflect an even more primary factor; that is, the ability to efficiently retain and access information in memory, thus allowing the child to reflect on the phonological components speech.

Given these considerations, we believe that several of these hypotheses ought to be further explored and tested. We suspected that a basic component in predicting performance in phonological awareness tasks is the ability to store and retain verbal information, which was measured here by word memory span tasks. This appeared to be the case in kindergarten, before formal reading instruction began for our sample. The question was whether this influence continued once reading instruction began, and children gained more sophisticated phonological recoding skills.

The results of our longitudinal analysis showed that the relationship of memory capacity and phonological awareness remained stable, and that memory capacity appeared to predict performance on phonological awareness tasks in both kindergarten and second grade. This indicates that the capacity to efficiently store and retain verbal information continues to have a significant influence on phonological processing, even during the second year of reading instruction. The efficiency of accessing and utilizing stored information about phonological codes is evidenced by decoding speed for words and pseudowords; and in turn, the ability to perform phonological awareness tasks (such as recognizing phoneme changes, and manipulation of phonemes) is affected by the limitations on memory capacity of the beginning reader.

For children in preschool and in the early elementary school grade, phonological recoding skill may not exert an influence on reading performance without a certain ability to efficiently retain and process verbal information. The results found here, taken together with those of Mann et al. (1980), Brady et al. (1983, 1987), and Hitch et al. (1988, 1989) suggest a developmental trend. Memory capacity affects the processing efficiency of phonological cues in preschool and in early elementary school. Then, to the degree which phonological awareness and recoding strategies are developed in preschool and automatized in early elementary school, these affect later decoding skills and text processing efficiency.

This suggests that concentrating on teaching to achieve phonological awareness in preschool and beginning elementary school should be accompanied by facilitating children's skills for efficient organization of verbal information in memory for an effect on reading performance, because phonological recoding skills depend upon the efficiency of memory. Only as children gain in their ability to simultaneously retain and access verbal information while mentally representing speech as consisting of phonemic components, will they be able to use phonological recoding as an efficient strategy in organizing speech and text for better decoding and ciphering of text.

One caution in drawing conclusions from our own study, as well as others using structural equation modelling, path analysis, or other confirmatory factor analyses is that the test statistics used $\left(\chi^{2}\right.$, in our case) are normally sensitive to sample size (see Cliff, 1983; Lomax, 1989). Our own study had relatively small sample size. Sample sizes around 100 or less generate fitting statistics for hypothesized models more often than larger sample sizes. Therefore, longitudinal studies designed to investigate causal relationships over time would do well to secure large sample sizes without, of course, sacrificing precision of measurement. In the case of small sample sizes, attention to GFI and RMR values provide additional information about the fit of models.

The next steps in investigating the longitudinal relationships of phonological encoding skills and memory capacity likely involve discovering if certain aspects of memory and 
information processing capacity can be facilitated for performing phonological awareness and recoding skills, in addition to discovering those phonological skills which can and should be developed early to enable children to become better readers. Discovering how young children process and access phonological components of speech, and which factors mediate this development (i.e., memory capacity, letter knowledge) may lead to suggestions for developing instructional tools which better prepare children for reading instruction.

\section{Notes}

1 The middle sound oddity measure was administered as well, but demonstrated a ceiling effect in our sample. Therefore it was not included in our models.

2 The path between verbal ability and phonological encoding was left in our model for comparison with a subsequent specified model, although its beta weight was not significant.

\section{References}

Bradley, L., \& Bryant, P. (1985). Rhyme and Reason in reading and Spelling. Ann Arbor, MI: University of Michigan Press.

Bryant, P., Bradley, L., MacLean, K., \& Crossland, J. (1989). Nursery rhymes, phonological skills, and reading. Journal of Child Language, 16, 407-428.

Brady, S., Mann, V., \& Schmidt, R. (1987). Errors in short term memory for good and poor readers. Memory and Cognition, $15,444-453$.

Brady, L., Shankweiler, D., \& Mann, V. (1983). Speech perception and memory coding in relation to reading ability. Journal of Experimental Child Psychology, 35, 345-367.

Brügelmann, H. (1986). Lese-und Schreibaufgaben für Schulanfänger. Universität Bremen: Studiengang Primarstufe.

Case, R., Kurland, D. M., \& Goldberg, J. (1982). Operacional efficiency and the growth of short-term memory span. Journal of Experimental Child Psychology, 33, 386-404.

Cliff, N. (1983). Some cautions concerning the application of causal modeling methods. Multivariate Behavioral Research, $18,115-126$.

Daneman, M., \& Blennerhasset, A. (1984). How to assess the listening comprehension skills of prereaders. Journal of Educational Psychology, 76, 1372-1381.

Dixon, P., LeFevre, J., \& Twilley, L. C. (1988). Word knowledge and working memory as predictors of reading skill. Journal of Educational Psychology, 80, 465-472.

Ehri, L.C. (1989). The development of spelling knowledge and its role in reading acquisition and reading disability. Journal of Learning Disabilities, 22, 356-365.

Eggert, D. (1978). Hannover-Wechsler Intelligenztest für das Vorschulalter (HAWIVA). Berne, Switzerland: Huber.

Guttentag, R., \& Haith, M. M. (1980). A longitudinal study of word processing by first-grade children. Journal of Educational Psychology, 72, 701-705.

Hitch, G. J. Halliday, M. S., Schaafstal, A. M., \& Schraagen, J. M. C. (1988). Visual working memory in young children. Memory and Cognition, 16, 120-132.

Hitch, G. J., Woodin, M. E., \& Baker, S. (1989). Visual and phonological components of working memory in children. Memory and Cognition, 17, 175-185.

Hogaboam, T. W., \& Perfetti, C. A. (1978). Reading skill and the role of verbal experience in decoding. Journal of Educational Psychology, 70, 717-729.

Jöreskog, K. G., \& Sörbom, D. (1984). LISREL VI: Analysis of Structural Relationships by the Method of Maximum Likelihood. Mooresville, IN: Scientific Software, Inc.

Kleiman, G. M. (1975). Speech recoding in reading. Journal of Verbal Learning and Verbal Behavior, 14, 323-339.

LaBerge, D., \& Samuels, S. J. (1974). Toward a theory of automatic information processing in reading. Cognitive Psychologist, 6, 293-323.

Lohmöller, J.-B. (1981). LVPLS 1.6 Program Manual: Latent variables path analysis with partial least-squares estimation. Forschungsbereich 81.04, Fachbereich Pädagogik. Neubiberg, W. Germany: Hochschule der Bundeswehr München.

Lomax, R. G. (1989). A guide of LISREL-type structural equation modeling. Behavior Research Methods and Instrumentation, 14, 1-8.

Lundberg, I., Olofsson, A., \& Wall, S. (1980). Reading and spelling skills in the first school years predicted from phonemic awareness skills in kindergarten. Scandinavian Journal of Psychology, 21, 159-173. 
Mann, V. A., Liberman, I. Y., \& Shankweiler, D. (1980). Children's memory for sentences and word strings in relation to reading ability. Memory and Cognition, 8, 329-335.

Näslund, J. C. (1988). Leseaufgaben (Reading comprehension test for German second graders). Munich, W. Germany: Max-Planck-Institute for Psychological Research.

Näslund, J. C., \& Schneider, W. (1989). The influence of verbal memory, phonological encoding, and letter knowledge on later reading performance in german children. Paper presented at the Third European Conference for Research on Learning and Instruction, Sept. 1989, Madrid, Spain.

Perfetti, C. A., \& Lesgold, A. M. (1978). Coding and comprehension in skilled reading and instruction. In L. B. Resnick \& P. A. Weaver (Eds.), Theory and practice of early reading, Vol. 1. (pp. 57-84). Hillsdale, NJ.: Lawrence Erlbaum Associations, Publishers.

Rott, C., \& Zielinski, W. (1986). Entwicklung der lesefertigkeit in der grundschule. Zeitschrift für Entwicklungspsychologie und Pädagogishe Psychologie, 18, 165-175.

Schneider , W., Näslund, J. C., \& Weinert, F. E. (1989). Prerequisites of school achievement. In F. E. Weinert \& W. Schneider (Eds.), The Munich longitudinal study on the genesis of individual competencies: Report n. 5: Results of wave three. (pp. 155-181).

Schneider, W., Sodian, B., Strube, G. \& Weinert, F. E. (1987). Prerequisites of school achievement. In F. E. Weinert \& W. Schneider (Eds.), The Munich longitudinal study on the genesis of individual competencies: Report $n .^{\circ} 2$. Documentation of assessment procedures used in waves one to three. (pp. 151-172). Munich, W. Germany: Max-Planck-Institute for Psychological Research.

Shankweiler, D., Liberman, I. Y., Mark, L. S., Fowler, C. A., \& Fischer, F. W. (1979). The speech code and learning to read. Journal of ExperimentalPsychology: Human Learning and Memory, 5, 531-545.

Siegel, L. S., \& Linder, B. A. (1984). Short-term memory processes in children with reading and arithmetic learning disabilities. Developmental Psychology, 20, 200-207.

Siegel, L. S., Ryan, E. B. (1989). The development of working memory in normally achieving and subtypes of learning disabled children. Child Development, 60, 973-980.

Stanovich, K. E., Cunningham, A. E., \& Cramer (1984). Assessing phonological awareness in kindergarten children: Issues of task comparability. Journal of Experimental Child Psychology, 38, 175-190.

Stanovich, K. E., Cunningham, A. E., \& Feeman, D. J. (1984). Intelligence, cognitive skills, and early reading progress. Reading Research Quarterly, 19, 278-303.

Tewes, U. (1983). Hamburg-Wechsler Intelligenztest für Kinder (HAWIK-R). Berne, Switzerland: Huber.

Tunmer, W. E., \& Nesdale, A. R. (1985). Phonetic segmentation skill and beginning reading. Journal of Educational Psychology, 77,, 417-427.

Valtin, R. (1984). Awareness of features and functions of language. In F. Downing \& R. Valtin (Eds.), Language awareness and learning to read, (pp. 227-260). N.Y.: Springer-Verlag.

Wagner, R. K., \& Torgesen, J. K. (1987). The nature of phonological processing and its causal role in the acquisition of reading skills. Psychological Bulletin, 101, 192-212.

Yuill, N., Oakhill, J., \& Parkin, A. (1989). Working memory, comprehension ability an the resolution of text anomaly. British Journal of Psychology, 80, 351-361.

Key words: Causal relationships, Decoding speed, Longitudinal effects, Memory capacity, Phonological awareness, Reading acquisition, Verbal ability.

Received: March 1990

Revision received: August 1990

Jan Carol Näslund. Institute für Psychologie, Universität Würzburg, Wittelsbacherplatz 1, D-8700 Würzburg, F.R.G.

\section{Current theme of research:}

Cognitive developmental factors affecting reading acquisition and automatization processes in learning cognitive and psychomotor tasks.

\section{Most relevant publications in the field of Educational Psychology:}

«The effect of automaticity on individual variation and retention». (1988). In H. Mandl, E. DeCorte, N. Bennett \& H. F. Friedrich (Eds.), Learning and Instruction : European Research in an International Context. Vol. 2.1: Social and Cognitive aspects of Learning and Instruction, (pp. 275-290). Oxford: Pergamon Press.

Näslund, J. C. (1990). Tha interrelationships among preschool predictors of reading acquisition for German children. Reading and Writing: An Interdisciplinary Journal, 2, 327-360. 
Näslund, J. C., \& Samuels, S. J. (1991). Automatic access to word sounds and meaning in decoding written text. The Reading and Writing Quarterly.

Schneider, W., \& Näslund, J. C. (1990). Cognitive prerequisites of reading and spelling: A longitudinal approach. To appear in A. Demetriou, M. Shayer \& A. Efklides (Eds.), The Modern Theories of Cognitive Development Go to School.

Wolfgang Schneider. Institute für Psychologie, Universität Würzburg, Wittelsbacherplatz 1, D-8700 Würzburg, F.R.G.

\section{Current theme of research:}

Development of memory and metamemory in children, Reading acquisition, Prediction of school achievement.

Most relevant publications in the field of Educational Psychology:

Schneider, W., \& Pressley, M. (1989). Memory development 2 and 20. New York: Springer.

Schneider, W., Korkel, J., \& Weinert, F. E. (1989). Domain-specific knowledge and memory performance: A comparison of high- and low-aptitude children. Journal of Educational Psychology, 81, 306-312.

Pressley, M., Borkowski, J. G., \& Schneider, W. (1990). Good information processing: What it is and how education can promote it. International Journal of Educational Research, 14, 857-867.

Schneider, W., \& Weinert, F. E. (Eds.) (1990). Interactions among aptitudes, strategies, and knowledge in cognitive performance. New-York: Springer-Verlag. 